\title{
Male Breast Metastasis from the Bladder Carcinoma: Case Report
}

\author{
I Adrif, S Daoudi, S Ouguellit, S Naciri, H Mrabti, H Errihani
}

\begin{abstract}
The most frequent sites of metastasis from primary bladder carcinoma are the lymph nodes, liver, lung and bone. Nevertheless many other areas have also been described.
\end{abstract}

Breast lesions secondary to urothelial tumors have been repported either in male or in female. The diagnosis of metastases is made on unilateral involvement and the appearance of a nodule closes easily palpable, ultrasound and mammography allow to confirm it and finally immunocytochemical studie is the gold standard in the identification of an unknown neoplasm in the male breast.

This type of neoplasm generally occurs in middle age, is usually diagnosed at an advanced stage and is usually associated with a poor prognosis.

We report a case of 64 year man with a breast metastasis of bladder carcinoma histologically proven.

Index Terms-About four key words or phrases in alphabetical order, separated by commas.

\section{INTRODUCTION}

Metastases to the breast from extramammary malignancies represent approximately $2 \%$ of malignant mammary tumors. Metastatic carcinoma in the male breast is even more exceptional than in the female [1].

Carcinoma of the bladder metastatic to the breast is only sporadically reported in the literature [2].

We report a case of 64 year man with a breast metastasis of bladder carcinoma histologically proven.

\section{CASE REPORT}

A 64-year-old man, followed since May 2017 for urothelial carcinoma of the bladder, surgically treated by radical cystectomy with a Briker-type shunt. A year later he presented a rapidly increasing lump in his right breast, and the extension workup did not show any further lesion.

ADRIF Imane, Department Of Medical Oncology, National Institute Of Oncology, Rabat, Morocco.

DAOUDI Sara, Department Of Medical Oncology, National Institute Of Oncology, Rabat, Morocco.

OUGUELLIT Sihame, Department Of Medical Oncology, National Institute Of Oncology, Rabat, Morocco.
The patient underwent a mastectomy with axillary dissection and the immunohistochemical study returned in favor of a breast location of a poorly differentiated carcinomatous process compatible with a bladder origin with; CK7 +, CK20 +, GAT3 + and Mammaglobulin -

He did not receive chemotherapy and did not show any other metastatic localization during 1 year of follow-up.

\section{DISCUSSION}

Male breast carcinoma represents only $1 \%$ of all breast tumours and $1 \%$ of all male malignancies [3], [4]. Clinically, the lesions are usually round, painless, without skin retraction or associated adenopathies (33\%) [2].

The mammographic criteria of male breast cancer are analogous to similar lesions in the female breast, and include a lesion usually eccentric to the nipple, with punctate microcalcification and irregularly spiculated margins, cutaneous thickening, and nipple and areolar retraction [1], [5]. Microcalcification can be the only sign of malignancy.Diagnosis, sometimes suggested by morphological study of the tumor, is confirmed by immunohistochemistry [2], [6].

The first case of carcinoma of the bladder metastatic to the male breast was reported by Truesdale et al in 1979 [7]. A poorly differentiated transitional cell carcinoma metastatic to the breast and suprasternal area was detected 7 months postcystectomy. The first detailed description of a case of transitional cell carcinoma of the bladder metastatic to the female breast was reported by Erkman et al in 1982 [8]. The patient was a 43-year-old woman who presented 3 months after a radical cystectomy two asymptomatic right breast masses as the first evidence of widely metastatic bladder carcinoma. Recently, breast metastasis originating from urinary bladder carcinoma has been described sporadically [2].This type of neoplasm is usually associated with a poor prognosis.

\section{CONCLUSION}

Breast metastases from bladder cancer are rare, only histological examination can confirm the primary or secondary nature of a breast lesion. 


\section{REFERENCES}

[1] s cappabianca and al. Metastasis to the male breast from carcinoma of the urinary bladder. The British Journal of Radiology, 73 (2000), $1326 \pm 1328$

[2] Yaomin Chen and al. Breast metastasis from signet ring cell carcinoma of the urinary bladder: A case report molecular and clinical oncology 5: 111-112, 2016

[3] Jackson VP, Gilmar R. Male breast carcinoma in gynecomastia. Radiology 1983;149:533 \pm 6 .

[4] Treves N, Holleb AI. Cancer in the male breast: a report of 146 cases. Cancer 1955;8:1239 \pm 50 .

[5] Panzarola P, Bosso P, Ercolani S. La mammografiae l'ecografia nella patologia mammaria maschile. Radiol Med 1992;84:32 \pm 5 .

[6] T. Lebret, A. Méjean Sites métastatiques atypiques des tumeurs urothéliales. Progrès en Urologie (2008), Suppl. 7, S289-S297.

[7] Truesdale BH, Johnson RD, Evins SC, et al: Carcinoma of bladder metastatic to breast. Urology 13: 430-431, 1979.

[8] Erkman AW, Markman M, Murphy JB and Lenhard RE Jr: Transitional cell carcinoma of the bladder metastatic to the breast. Med Pediatr Oncol 10: 141-144, 1982 